\title{
Strong convergence theorems for the general split common fixed point problem in Hilbert spaces
}

\author{
Rudong Chen, ${ }^{\mathrm{a}, *}$, Tao Sun ${ }^{\mathrm{a}}$, Huimin $\mathrm{He}^{\mathrm{b}}$, Jen-Chih Yao ${ }^{\mathrm{c}}$ \\ a Department of Mathematics, Tian jin Polytechnic University, Tian jin 300387, China. \\ ${ }^{b}$ School of Mathematics and Statistics, Xidian University, Xi'an 710071, China. \\ ${ }^{c}$ Center for General Education, China Medical University, Taichung 40402, Taiwan, ROC.
}

Communicated by X. Qin

\begin{abstract}
In this paper, we propose and investigate a new iterative algorithm for solving the general split common fixed point problem in the setting of infinite-dimensional Hilbert spaces. We also prove the sequence generated by the proposed algorithm converge strongly to a common solution of the general split common fixed point problem. As application, some particular cases of directed operator and quasi-nonexpansive operator are also considered. Finally, we present several numerical results for general split common fixed point problem to demonstrate the efficiency of the proposed algorithm. (c)2017 All rights reserved.
\end{abstract}

Keywords: General split common fixed point problem, demicontractive operator, quasi-nonexpansive operator, directed operator.

2010 MSC: 47J25, 47H09, 65J25.

\section{Introduction}

The split feasibility problem was first introduced in 1994 by Censor and Elfving [4]. Let $\mathrm{H}_{1}$ and $\mathrm{H}_{2}$ be real Hilbert spaces, $C$ and $Q$ be two nonempty closed convex sets of $\mathrm{H}_{2}$ and $\mathrm{H}_{2}$, respectively. Let A : $\mathrm{H}_{1} \longmapsto \mathrm{H}_{2}$ be a bounded linear operator. The split feasibility problem SFP is formulated as to find a point $x \in C$ such that

$$
x \in C \text { and } A x \in Q .
$$

Throughout this paper, we use $S$ to denote the solution set of the SFP, that is

$$
S=\left\{x \in H_{1} \mid x \in C, A x \in Q\right\} .
$$

As we know, the SFP has received much attention due to its application in intensity-modulated radiation therapy, signal processing, and image reconstruction, for instance $[2,3,5,6,8,9,11,12,14,16$, 17].

\footnotetext{
*Corresponding author

Email addresses: chenrd@tjpu.edu.cn (Rudong Chen), 1639690598@qq.com (Tao Sun), huiminhe@126.com (Huimin He), yaojc@mail.cmu.edu.tw (Jen-Chih Yao)

doi:10.22436/jnsa.010.10.27
} 
To solve the SFP, an algorithm called the CQ-algorithm was proposed by Byrne [1, 2]as the following:

$$
x_{n+1}=P_{C}\left(x_{n}-\rho A^{*}\left(I-P_{Q}\right) A x_{n}\right), \quad n \geqslant 0,
$$

where $0<\rho<2 /\|A\|^{2}$ and $\mathrm{P}_{\mathrm{Q}}$ denotes the nearest point projection from $\mathrm{H}_{2}$ onto $\mathrm{Q}$. The sequence generated by CQ-algorithm converges to a solution of the SFP for any starting point $x_{0} \in \mathrm{H}_{1}$, whenever the SFP has a solution. However, when the split feasibility problem has no solution, the sequence generated by CQ-algorithm converges to a minimizer of $\left\|\mathrm{P}_{\mathrm{Q}}(A z)-A z\right\|$ over all $z \in C$, whenever such a minimizer exists.

Split common fixed point problem is a generalization of the split feasibility problem, which is an inverse problem that consists of finding an element in a fixed point set of some operator, whose image under a bounded linear operator is an element of another fixed point set of operator. Split common fixed point problem SCFP is finding a point $x \in \mathrm{H}_{1}$, with the property:

$$
x \in \operatorname{Fix}(U) \text { such that } A x \in \operatorname{Fix}(T),
$$

where Fix $(\mathrm{U})$ and Fix $(T)$ denote the fixed point sets of nonlinear operators $\mathrm{U}: \mathrm{H}_{1} \longmapsto \mathrm{H}_{1}$ and $\mathrm{T}: \mathrm{H}_{2} \longmapsto$ $\mathrm{H}_{2}$, respectively. A is a bounded linear operator. This problem was introduced by Censor and Segal [6], who proposed the following algorithm for solving such a problem. For given $x_{0} \in \mathrm{H}_{1}$, then iterative sequence $\left\{x_{n}\right\}$ is generated as follows:

$$
x_{n+1}=U\left(I-\rho A^{*}(I-T) A\right) x_{n}, \quad n \geqslant 0,
$$

where $\mathrm{U}$ and $\mathrm{T}$ are two directed operators. This algorithm was extended to the case of finitely many directed operators by Wang and Xu [14], quasi-nonexpansive operators by Moudafi [12], and demicontractive mappings by Moudafi [11]. Recently, Cui and Wang [9] proposed the following iterative method to solve the problem (1.1). For given $x_{0} \in H_{1}$ and $\lambda \in(0,1-\tau)$, the iterative sequence $\left\{x_{n}\right\}$ is generated as follows:

$$
x_{n+1}=U_{\lambda}\left(x_{n}-\rho_{n} A^{*}(I-T) A x_{n}\right), \quad n \geqslant 0,
$$

where $\mathrm{H}_{1}, \mathrm{H}_{2}$ are two real Hilbert spaces, $\mathrm{U}: \mathrm{H}_{1} \rightarrow \mathrm{H}_{1}$ is a $\mathrm{k}$-demicontractive operator with $\mathrm{k}<1$, and $\mathrm{T}: \mathrm{H}_{2} \rightarrow \mathrm{H}_{2}$ is a $\tau$-demicontractive operator with $\tau<1$. Denote $\mathrm{U}_{\lambda}:=(1-\lambda) \mathrm{I}+\lambda \mathrm{U}$ a $\lambda$ relaxation of the operator U. A is a bounded linear operator with adjoint $A^{*}$ and the step size $\rho_{n}$ is chosen in such a way that

$$
\begin{cases}\rho_{n}=\frac{(1-\tau)\left\|(I-T) A x_{n}\right\|^{2}}{2\left\|A^{*}(I-T) A x_{n}\right\|^{2}}, & A x_{n} \neq T\left(A x_{n}\right), \\ \rho_{n}=0, & \text { otherwise. }\end{cases}
$$

and they proved the sequence converges weakly to a solution of the SCFP.

Motivated and inspired by Cui and Wang's work [9], we consider the general split common fixed point problem GSCFP and construct an algorithm for demicontractive operators that produces sequences that always converge strongly to a solution of GSCFP and whose step size does not depend on the norm of the operator A. The constructed algorithm is Halpern type [10]. We also consider particular cases such as directed operators and quasi-nonexpansive mappings.

$$
\text { Find } x \in \bigcap_{i=1}^{\infty} \operatorname{Fix}\left(\mathrm{U}^{i}\right) \text { such that } A x \in \bigcap_{i=1}^{\infty} \operatorname{Fix}\left(T_{i}\right) \text {, }
$$

where $\mathrm{H}_{1}, \mathrm{H}_{2}$ are real Hilbert spaces, $\mathrm{U}^{i}: \mathrm{H}_{1} \longmapsto \mathrm{H}_{1}$ is a $\mathrm{k}_{\mathrm{i}}$-demicontractive operator with $\mathrm{k}_{\mathrm{i}}<1$, $\mathrm{T}_{i}: \mathrm{H}_{2} \longmapsto \mathrm{H}_{2}$ is a $\tau_{i}$-demicontractive operator with $\tau_{i}<1, i=1,2, \ldots, \infty . A: H_{1} \longmapsto \mathrm{H}_{2}$ is a bounded linear operator. 
In this paper, we will introduce a more general iterative method for GSCFP (1.3) and fixed point problem, which is defined in the following way:

$$
x_{n+1}=\alpha_{n} v+\beta_{n} x_{n}+\sum_{i=1}^{\infty} \gamma_{n, i} u_{\lambda_{i}}^{i}\left(x_{n}-\rho_{n, i} A^{*}\left(I-T_{i}\right) A x_{n}\right), \quad n \geqslant 0,
$$

where $\alpha_{n}, \beta_{n}, \gamma_{n, i} \in(0,1), v \in H_{1}$ and $\alpha_{n}+\beta_{n}+\sum_{i=1}^{\infty} \gamma_{n, i}=1 ; u_{\lambda_{i}}^{i}:=\left(1-\lambda_{i}\right) I+\lambda_{i} u^{i}$. Note that, if $i=1, \alpha_{n}=\beta_{n}=0, \gamma_{n}=1$, scheme (1.4) can be reduced to (1.2).

Meanwhile, we will prove the sequence generated by (1.4) converges strongly to a common element of the solution set of the GSCFP, and what is more important is that when $v=0$, the $\left\{x_{n}\right\}$ generated by (1.4) converges strongly to the minimum norm solution of the GSCFP. As application, particular cases of directed operator and quasi-nonexpansive operator are also considered. Finally, we present several numerical results for the general split common fixed point problem to demonstrate the efficiency of the proposed algorithm.

\section{Preliminaries}

We first recall some definitions, notations and conclusions which will be used in the proof of our main results. Let $\mathrm{H}$ be a real Hilbert space with inner product $\langle\cdot, \cdot\rangle$ and the norm $\|\cdot\|$. We denote by " $\rightarrow$ " strong convergence, by $\rightarrow$ weak convergence. In order to establish our convergence theorem, we need the following definition.

\section{Definition 2.1.}

(1) A mapping $\mathrm{T}: \mathrm{H} \longmapsto \mathrm{H}$ is nonexpansive if

$$
\|\mathrm{T} x-\mathrm{T} y\| \leqslant\|x-y\|, \quad \forall x, y \in H .
$$

(2) A mapping $P_{C}$ is called the metric (nearest point) projection of $H$ onto $C$, if $P_{C} x$ is the unique point in $\mathrm{C}$ with the property

$$
\left\|x-P_{C} x\right\|=\min \{\|x-y\|: y \in C\}, \forall x \in H .
$$

It is well-known that $P_{C}$ is nonexpansive mapping of $H$ onto $C$ and it is characterized as follows: given $x \in H$, there holds the inequality

$$
\left\langle x-P_{C} x, y-P_{C} x\right\rangle \leqslant 0, \quad \forall y \in C .
$$

Note that (2.1) is equivalent to

$$
\left\|P_{C} x-y\right\|^{2} \leqslant\|x-y\|^{2}-\left\|x-P_{C} x\right\|^{2} .
$$

(3) A mapping $T: H \longmapsto H$ is said to be quasi-nonexpansive if the fixed point of $T$, given by $\operatorname{Fix}(T):=\{x \in$ $H \mid T x=x\}$, is not empty and for all $z \in \operatorname{Fix}(T), x \in H$

$$
\|T x-z\| \leqslant\|x-z\| \text {. }
$$

(4) (Demiclosedness-principle) Let $\mathrm{C}$ be a nonempty closed convex subset of $\mathrm{H}$, and let $\mathrm{T}$ : $\mathrm{C} \longmapsto \mathrm{C}$ be a non-expansive mapping with $\operatorname{Fix}(T) \neq \emptyset$. Then $\mathrm{I}-\mathrm{T}$ is said to be demiclosed at zero, that is, if for any sequence $\left\{x_{n}\right\} \subset C$ with $x_{n} \rightarrow x \in C$ and $\left\|x_{n}-T x_{n}\right\| \rightarrow 0$, then $x=T x$.

(5) Let $T: H \rightarrow H$ be an operator with $\operatorname{Fix}(T) \neq \phi$. Then, for all $z \in \operatorname{Fix}(T)$ and $x \in H, T$ is

1. $\tau$-demicontractive with $\tau<1$ if

$$
\|\mathrm{T} x-z\|^{2} \leqslant\|x-z\|^{2}+\tau\|x-\mathrm{T} x\|^{2}, \quad \forall z \in \operatorname{Fix}(\mathrm{T}) .
$$

It is easy to verify that (2.2) is equivalent to

$$
\langle z-x, x-T x\rangle \leqslant \frac{\tau-1}{2}\|x-T x\|^{2}, x \in H .
$$


2. If $\tau=0$, then the inequality (2.2) becomes

$$
\|\mathrm{T} x-z\| \leqslant\|x-z\|, \quad \forall z \in \operatorname{Fix}(\mathrm{T}) .
$$

In the case $T$ is a quasi-nonexpansive operator.

3. If $\tau=-1$, then the inequality (2.2) becomes

$$
\|\mathrm{T} x-z\|^{2} \leqslant\|x-z\|^{2}+(-1)\|x-\mathrm{T} x\|^{2}, \quad \forall z \in \operatorname{Fix}(\mathrm{T}) .
$$

In the case $T$ is a directed operator, it is easy to verify that (2.3) is equivalent to

$$
\langle z-T x, x-T x\rangle \leqslant 0, \quad \forall z \in \operatorname{Fix}(T) .
$$

Proposition 2.2 ([7]). In Hilbert spaces, the following inequality holds,

$$
\|x+y\|^{2} \leqslant\|x\|^{2}+2\langle y, x+y\rangle, \quad \forall x, y \in H .
$$

Proposition 2.3 ([13]). Let $H$ be a real Hilbert space, and $\left\{x_{n}\right\}$ be a sequence in $H$. Then, for any given sequence $\left\{\alpha_{n}\right\}$ of positive numbers with $\sum_{n=1}^{\infty} \alpha_{n}=1$ for any positive integers $i, j$ with $i<j$ the following holds:

$$
\left\|\sum_{n=1}^{\infty} \alpha_{n} x_{n}\right\|^{2} \leqslant \sum_{n=1}^{\infty} \alpha_{n}\left\|x_{n}\right\|^{2}-\alpha_{i} \alpha_{j}\left\|x_{i}-x_{j}\right\|^{2} .
$$

Lemma 2.4 ([9]). Let $\mathrm{A}: \mathrm{H}_{1} \longmapsto \mathrm{H}_{2}$ be a bounded linear operator and $\mathrm{T}: \mathrm{H}_{2} \longmapsto \mathrm{H}_{2}$ be a $\tau$-demicontractive operator with $\tau<1$. If $A^{-1}(\operatorname{Fix}(T)) \neq \emptyset$, then:

(1) $(\mathrm{I}-\mathrm{T}) \mathrm{Ax}=0 \Leftrightarrow \mathrm{A}^{*}(\mathrm{I}-\mathrm{T}) \mathrm{Ax}=0, \forall x \in \mathrm{H}$;

(2) in addition, for $z \in A^{-1}(\operatorname{Fix}(T))$

$$
\left\|x-\rho A^{*}(I-T) A x-z\right\|^{2} \leqslant\|x-z\|^{2}-\frac{(1-\tau)^{2}}{4} \frac{\|(I-T) A x\|^{4}}{\left\|A^{*}(I-T) A x\right\|^{2}}
$$

where $x \in \mathrm{H}, \mathrm{Ax} \neq \mathrm{T} x$ and

$$
\rho:=\frac{(1-\tau)}{2} \frac{\|(I-T) A x\|^{2}}{\left\|A^{*}(I-T) A x\right\|^{2}}
$$

Lemma 2.5 ([9]). Let $\mathrm{U}: \mathrm{H} \longmapsto \mathrm{H}$ be a $\mathrm{k}$-demicontractive operator with $\mathrm{k}<1$. Denote $\mathrm{U}_{\lambda}:=(1-\lambda) \mathrm{I}+\lambda \mathrm{U}$ a $\lambda$ relaxation of the operator $U$, where $\lambda \in(0,1-\mathrm{k})$. Then for all $\mathrm{x} \in \mathrm{H}$ and $z \in \operatorname{Fix}(\mathrm{U})$

$$
\left\|\mathrm{U}_{\lambda} x-z\right\|^{2} \leqslant\|x-z\|^{2}-\lambda(1-k-\lambda)\|x-\mathrm{U} x\|^{2} .
$$

Clearly, $z \in \operatorname{Fix}(\mathrm{U})$ if and only if $z \in \operatorname{Fix}\left(\mathrm{U}_{\lambda}\right)$.

Lemma 2.6 ([15]). Assume $\left\{a_{n}\right\}$ is a sequence of non-negative real numbers satisfying:

$$
a_{n+1} \leqslant\left(1-\alpha_{n}\right) a_{n}+\alpha_{n} b_{n}+c_{n}, \quad n \geqslant 0,
$$

where $\left\{\alpha_{n}\right\},\left\{b_{n}\right\},\left\{c_{n}\right\}$ satisfy the following conditions:

(i) $\alpha_{n} \in[0,1]$, with $\sum_{n=0}^{\infty} \alpha_{n}=\infty$;

(ii) $c_{n} \geqslant 0$ for all $n \geqslant 0$ with $\sum_{n=0}^{\infty} c_{n} \leqslant \infty$;

(iii) $\limsup _{n \rightarrow \infty} b_{n} \leqslant 0$.

Then, $\lim _{n \rightarrow \infty} a_{n}=0$. 
Lemma 2.7 ([10]). Let $\left\{S_{n}\right\}$ be a sequence of real numbers that does not decrease at infinity, in the sense that there exists a subsequence $\left\{S_{n_{j}}\right\}_{j} \geqslant 0$ of $\left\{S_{n}\right\}$ such that

$$
\left\{\mathrm{S}_{\mathfrak{n}_{\mathrm{j}}}\right\}<\left\{\mathrm{S}_{\mathrm{n}_{\mathrm{j}}+1}\right\} \text { for all } \mathrm{j} \geqslant 0 .
$$

Also consider the sequence of the integers $\{\eta(n)\}_{n} \geqslant n_{0}$ defined by

$$
\eta(n)=\max \left\{k \leqslant n \mid S_{k}<S_{k+1}\right\} .
$$

Then $\{\eta(n)\}_{n \geqslant n_{0}}$ is a nondecreasing sequence verifying $\lim _{n \rightarrow \infty} \eta(n)=\infty$, and for all $n \geqslant n_{0}$, the following two estimates hold:

$$
S_{\eta(n)} \leqslant S_{\eta(n)+1}, \quad S_{n} \leqslant S_{\eta(n)+1} .
$$

\section{Strong convergence theorems for GSCFP}

Throughout this section, we propose an iterative method for solving the GSCFP and prove the theoretical convergence.

We denote $\Gamma$ the solutions of set the GSCFP (1.3).

$$
\Gamma=\left\{x^{*} \in \bigcap_{i=1}^{\infty} \operatorname{Fix}\left(\mathrm{U}^{i}\right), A x^{*} \in \bigcap_{i=1}^{\infty} \operatorname{Fix}\left(\mathrm{T}_{i}\right)\right\} .
$$

Proposition 3.1. Denote $t_{n}=x_{n}-\rho_{n, i} A^{*}\left(I-T_{i}\right) A x_{n}$, if $\rho_{n, i} \neq 0$, and take an $\hat{x} \in \Gamma$, arbitrarily. We derive from (2.6) and (2.7)

$$
\begin{aligned}
\left\|\mathrm{U}_{\lambda_{i}}^{i} t_{n}-\hat{x}\right\|^{2} & \leqslant\left\|t_{n}-\hat{x}\right\|^{2}-\lambda_{i}\left(1-\lambda_{i}-\kappa_{i}\right)\left\|t_{n}-u^{i} t_{n}\right\|^{2} \\
& =\left\|x_{n}-\rho_{n, i} A^{*}\left(I-T_{i}\right) A x_{n}-\hat{x}\right\|^{2}-\lambda_{i}\left(1-\lambda_{i}-\kappa_{i}\right)\left\|t_{n}-u^{i} t_{n}\right\|^{2} \\
& \leqslant\left\|x_{n}-\hat{x}\right\|^{2}-\frac{\left(1-\tau_{i}\right)^{2}}{4} \frac{\left\|\left(I-T_{i}\right) A x\right\|^{4}}{\left\|A^{*}\left(I-T_{i}\right) A x\right\|^{2}}-\lambda_{i}\left(1-\lambda_{i}-\kappa_{i}\right)\left\|t_{n}-u^{i} t_{n}\right\|^{2} \leqslant\left\|x_{n}-\hat{x}\right\|^{2} .
\end{aligned}
$$

On the other hand, in the case $\rho_{n, i}=0$, then $t_{n}=x_{n}$, we derive from (2.7)

$$
\left\|u_{\lambda_{i}}^{i} x_{n}-\hat{x}\right\|^{2} \leqslant\left\|x_{n}-\hat{x}\right\|^{2}-\lambda_{i}\left(1-\lambda_{i}-\kappa_{i}\right)\left\|x_{n}-u^{i} x_{n}\right\|^{2} \leqslant\left\|x_{n}-\hat{x}\right\|^{2} .
$$

Next we prove the strong convergence of the sequence generated by the iterative method (1.4). Denote $\mathrm{P}_{\Gamma} v$ is the metric (nearest point) projection of $v$ onto $\Gamma$.

Theorem 3.2. Let $\mathrm{H}_{1}, \mathrm{H}_{2}, \mathrm{~A}, \mathrm{~A}^{*}, \mathrm{U}^{i}, \mathrm{~T}_{i}$ be the same as above, and assume that the solution set $\Gamma$ is nonempty. If the sequences $\left\{\alpha_{n}\right\},\left\{\beta_{n}\right\},\left\{\gamma_{n, i}\right\}$ satisfy the following conditions:

(i) $\alpha_{n}, \beta_{n}, \gamma_{n, i} \in(0,1)$;

(ii) $\alpha_{n}+\beta_{n}+\sum_{i=1}^{\infty} \gamma_{n, i}=1$;

(iii) $\lim _{n \rightarrow \infty} \alpha_{n}=0$ and $\sum_{n=0}^{\infty} \alpha_{n}=\infty$,

then the sequence $\left\{x_{n}\right\}$ converges generated by iterative method (1.4) strongly to a point $x^{*}$, where $x^{*}$ is the nearest to $v$, that is $x^{*}=\mathrm{P}_{\Gamma} v$.

Proof. We divide the proof into three steps.

Step 1 . We prove that the following inequality holds:

$$
\left\|x_{n+1}-x^{*}\right\|^{2} \leqslant\left(1-\alpha_{n}\right)\left\|x_{n}-x^{*}\right\|^{2}+2 \alpha_{n}\left\langle v-x^{*}, x_{n+1}-x^{*}\right\rangle .
$$


For the case $\rho_{n, i} \neq 0$, from (2.4), (2.5), and (3.3), we have

$$
\begin{aligned}
\left\|x_{n+1}-x^{*}\right\|^{2} \leqslant & \left\|\beta_{n}\left(x_{n}-x^{*}\right)+\sum_{i=1}^{\infty} \gamma_{n, i}\left(U_{\lambda_{i}}^{i} t_{n}-x^{*}\right)\right\|^{2}+2 \alpha_{n}\left\langle v-x^{*}, x_{n+1}-x^{*}\right\rangle \\
\leqslant & \beta_{n}\left\|x_{n}-\hat{x}\right\|^{2}+\sum_{i=1}^{\infty} \gamma_{n, i}\left\|u_{\lambda_{i}}^{i} t_{n}-x^{*}\right\|^{2}+2 \alpha_{n}\left\langle v-x^{*}, x_{n+1}-x^{*}\right\rangle \\
\leqslant & \beta_{n}\left\|x_{n}-x^{*}\right\|^{2}+\sum_{i=1}^{\infty} \gamma_{n, i}\left[\left\|x_{n}-x^{*}\right\|^{2}-\frac{(1-\tau)^{2}}{4} \frac{\left\|\left(I-T_{i}\right) A x\right\|^{4}}{\left\|A^{*}\left(I-T_{i}\right) A x\right\|^{2}}\right] \\
& -\sum_{i=1}^{\infty} \gamma_{n, i} \lambda_{i}\left(1-\lambda_{i}-\kappa_{i}\right)\left\|t_{n}-U^{i} t_{n}\right\|^{2}+2 \alpha_{n}\left\langle v-x^{*}, x_{n+1}-x^{*}\right\rangle \\
\leqslant & \beta_{n}\left\|x_{n}-x^{*}\right\|^{2}+\sum_{i=1}^{\infty} \gamma_{n, i}\left\|x_{n}-\hat{x}\right\|^{2}+2 \alpha_{n}\left\langle v-x^{*}, x_{n+1}-x^{*}\right\rangle \\
= & \left(1-\alpha_{n}\right)\left\|x_{n}-x^{*}\right\|^{2}+2 \alpha_{n}\left\langle v-x^{*}, x_{n+1}-x^{*}\right\rangle .
\end{aligned}
$$

For the case $\rho_{n, i}=0$, from (2.4), (2.5), and (3.2), we have

$$
\begin{aligned}
\left\|x_{n+1}-x^{*}\right\|^{2} \leqslant & \left\|\beta_{n}\left(x_{n}-x^{*}\right)+\sum_{i=1}^{\infty} \gamma_{n, i}\left(u_{\lambda_{i}}^{i} x_{n}-x^{*}\right)\right\|^{2}+2 \alpha_{n}\left\langle v-x^{*}, x_{n+1}-x^{*}\right\rangle \\
\leqslant & \beta_{n}\left\|x_{n}-x^{*}\right\|^{2}+\sum_{i=1}^{\infty} \gamma_{n, i}\left\|u_{\lambda_{i}}^{i} x_{n}-x^{*}\right\|^{2}+2 \alpha_{n}\left\langle v-x^{*}, x_{n+1}-x^{*}\right\rangle \\
\leqslant & \beta_{n}\left\|x_{n}-x^{*}\right\|^{2}+\sum_{i=1}^{\infty} \gamma_{n, i}\left[\left\|x_{n}-x^{*}\right\|^{2}-\lambda_{i}\left(1-\lambda_{i}-\kappa_{i}\right)\left\|x_{n}-u^{i} x_{n}\right\|^{2}\right] \\
& +2 \alpha_{n}\left\langle v-x^{*}, x_{n+1}-x^{*}\right\rangle \\
\leqslant & \beta_{n}\left\|x_{n}-x^{*}\right\|^{2}+\sum_{i=1}^{\infty} \gamma_{n, i}\left\|x_{n}-x^{*}\right\|^{2}+2 \alpha_{n}\left\langle v-x^{*}, x_{n+1}-x^{*}\right\rangle \\
= & \left(1-\alpha_{n}\right)\left\|x_{n}-x^{*}\right\|^{2}+2 \alpha_{n}\left\langle v-x^{*}, x_{n+1}-x^{*}\right\rangle .
\end{aligned}
$$

Therefore, the inequality (3.4) is proved.

Step 2. We show that the sequence $\left\{x_{n}\right\}$ is bounded, and take an $\hat{x} \in \Gamma$, arbitrarily.

We will prove that the following inequality holds:

$$
\left\|x_{n}-\hat{x}\right\|^{2} \leqslant \max \left\{\|v-\hat{x}\|^{2},\left\|x_{0}-\hat{x}\right\|^{2}\right\} .
$$

If $\rho_{n, i} \neq 0$, from (3.1), (2.5), and (3.2), we get

$$
\begin{aligned}
\left\|x_{n+1}-\hat{x}\right\|^{2} & =\left\|\alpha_{n}(v-\hat{x})+\beta_{n}\left(x_{n}-\hat{x}\right)+\sum_{i=1}^{\infty} \gamma_{n, i}\left(u_{\lambda_{i}}^{i} t_{n}-\hat{x}\right)\right\|^{2} \\
& \leqslant \alpha_{n}\|v-\hat{x}\|^{2}+\beta_{n}\left\|x_{n}-\hat{x}\right\|^{2}+\sum_{i=1}^{\infty} \gamma_{n, i}\left\|u_{\lambda_{i}}^{i} t_{n}-\hat{x}\right\|^{2} \\
& \leqslant \alpha_{n}\|v-\hat{x}\|^{2}+\beta_{n}\left\|x_{n}-\hat{x}\right\|^{2}+\sum_{i=1}^{\infty} \gamma_{n, i}\left\|x_{n}-\hat{x}\right\|^{2} \\
& =\alpha_{n}\|v-\hat{x}\|^{2}+\left(1-\alpha_{n}\right)\left\|x_{n}-\hat{x}\right\|^{2} \\
& \leqslant \max \left\{\|v-\hat{x}\|^{2},\left\|x_{n}-\hat{x}\right\|^{2}\right\}
\end{aligned}
$$




$$
\leqslant \max \left\{\|v-\hat{x}\|^{2},\left\|x_{0}-\hat{x}\right\|^{2}\right\}
$$

For the case $\rho_{n, i}=0$, we have $t_{n}=x_{n}$ and by (3.1), (2.5), and (3.3), we get

$$
\begin{aligned}
\left\|x_{n+1}-\hat{x}\right\|^{2} & =\left\|\alpha_{n}(v-\hat{x})+\beta_{n}\left(x_{n}-\hat{x}\right)+\sum_{i=1}^{\infty} \gamma_{n, i}\left(u_{\lambda_{i}}^{i} x_{n}-\hat{x}\right)\right\|^{2} \\
& \leqslant \alpha_{n}\|v-\hat{x}\|^{2}+\beta_{n}\left\|x_{n}-\hat{x}\right\|^{2}+\sum_{i=1}^{\infty} \gamma_{n, i}\left\|u_{\lambda_{i}}^{i} x_{n}-\hat{x}\right\|^{2} \\
& \leqslant \alpha_{n}\|v-\hat{x}\|^{2}+\beta_{n}\left\|x_{n}-\hat{x}\right\|^{2}+\sum_{i=1}^{\infty} \gamma_{n, i}\left\|x_{n}-\hat{x}\right\|^{2} \\
& =\alpha_{n}\|v-\hat{x}\|^{2}+\left(1-\alpha_{n}\right)\left\|x_{n}-\hat{x}\right\|^{2} \\
& \leqslant \max \left\{\|v-\hat{x}\|^{2},\left\|x_{n}-\hat{x}\right\|^{2}\right\} \\
& \vdots \\
& \leqslant \max \left\{\|v-\hat{x}\|^{2},\left\|x_{0}-\hat{x}\right\|^{2}\right\} .
\end{aligned}
$$

Therefore, the inequality (3.7) is proved and this implies that the sequence $\left\{x_{n}\right\}$ is bounded.

Step 3. Let $y_{n}:=\left\|x_{n}-x^{*}\right\|^{2}$ and we prove $\left\{y_{n}\right\}$ converges strongly to zero by considering two cases on the sequence $\left\{y_{n}\right\}$.

Case 1: Suppose that $\left\{y_{n}\right\}$ is a monotone sequence, since $\left\{x_{n}\right\}$ is bounded, it follows that $\left\{y_{n}\right\}$ is convergent. For the case $\rho_{n, i} \neq 0$, let $u_{n, i}=\gamma_{n, i} \lambda_{i}\left(1-\lambda_{i}-\kappa_{i}\right)\left\|t_{n}-U^{i} t_{n}\right\|^{2}+\frac{(1-\tau)^{2}}{4} \frac{\left\|\left(I-T_{i}\right) A x_{n}\right\|^{4}}{\left\|A^{*}\left(I-T_{i}\right) A x_{n}\right\|^{2}}$, by (3.5) and the boundedness of the sequence $\left\{x_{n}\right\}$, there exists a constant $L_{1}>0$, such that

$$
\begin{aligned}
\sum_{i=1}^{\infty} \gamma_{n, i} u_{n, i} & \leqslant\left(y_{n}-y_{n+1}\right)+2 \alpha_{n}\left\langle v-x^{*}, x_{n+1}-x^{*}\right\rangle \\
& \leqslant\left(y_{n}-y_{n+1}\right)+2 \alpha_{n}\left\|v-x^{*}\right\|\left\|x_{n+1}-x^{*}\right\| \\
& \leqslant\left(y_{n}-y_{n+1}\right)+\alpha_{n} L_{1} .
\end{aligned}
$$

Take on both sides of the inequality limits and by the fact that $\left\{y_{n}\right\}$ is convergent, we get

$$
\lim _{n \rightarrow \infty} u_{n, i}=0
$$

In other words,

$$
\lim _{n \rightarrow \infty}\left\|t_{n}-U^{i} t_{n}\right\|^{2}=\lim _{n \rightarrow \infty} \frac{(1-\tau)^{2}}{4} \frac{\left\|\left(I-T_{i}\right) A x_{n}\right\|^{4}}{\left\|A^{*}\left(I-T_{i}\right) A x_{n}\right\|^{2}}=0 .
$$

If $\rho_{n, i}=0$, then, clearly $\left(I-T_{i}\right) A x_{n}=0$ and it follows from (3.6) and the boundedness of the sequence $\left\{x_{n}\right\}$, there exists a constant $L_{1}>0$ such that

$$
\begin{aligned}
\sum_{i=1}^{\infty} \gamma_{n, i} \lambda_{i}\left(1-\lambda_{i}-\kappa_{i}\right)\left\|x_{n}-u^{i} x_{n}\right\|^{2} & \leqslant\left(y_{n}-y_{n+1}\right)+2 \alpha_{n}\left\langle v-x^{*}, x_{n+1}-x^{*}\right\rangle \\
& \leqslant\left(y_{n}-y_{n+1}\right)+2 \alpha_{n}\left\|v-x^{*}\right\|\left\|x_{n+1}-x^{*}\right\| \\
& \leqslant\left(y_{n}-y_{n+1}\right)+\alpha_{n} L_{1} .
\end{aligned}
$$


Take on both sides of the inequality limits and by the fact that $\left\{y_{n}\right\}$ is convergent, we arrive at

$$
\lim _{n \rightarrow \infty}\left\|x_{n}-u_{i} x_{n}\right\|^{2}=0 \text {. }
$$

By (3.8) and (3.9), we get

$$
\lim _{n \rightarrow \infty}\left\|x_{n}-U_{i} x_{n}\right\|^{2}=\lim _{n \rightarrow \infty}\left\|t_{n}-u_{i} t_{n}\right\|^{2}=\lim _{n \rightarrow \infty} \frac{(1-\tau)^{2}}{4} \frac{\left\|\left(I-T_{i}\right) A x_{n}\right\|^{4}}{\left\|A^{*}\left(I-T_{i}\right) A x_{n}\right\|^{2}}=0 .
$$

Now suppose $\left\{x_{n_{k}}\right\}$ is a subsequence of $\left\{x_{n}\right\}$ that converges weakly to $z$ such that

$$
\limsup _{n \rightarrow \infty}\left\langle v-x^{*}, x_{n}-x^{*}\right\rangle=\lim _{k \rightarrow \infty}\left\langle v-x^{*}, x_{n_{k}}-x^{*}\right\rangle=\left\langle v-x^{*}, z-x^{*}\right\rangle .
$$

For $\rho_{n, i} \neq 0$, we have from the definitions of $t_{n}$ and $\rho_{n, i}$ that

$$
\left\|t_{n}-x_{n}\right\|=\rho_{n, i}\left\|A *\left(I-T_{i}\right) A x_{n}\right\|=\frac{1-\tau_{i}}{2} \frac{\left\|\left(I-T_{i}\right) A x_{n}\right\|^{2}}{\left\|A *\left(I-T_{i}\right) A x_{n}\right\|} .
$$

Moreover,

$$
\frac{1}{\|A\|}\left\|\left(I-T_{i}\right) A x_{n}\right\|=\frac{\left\|\left(I-T_{i}\right) A x_{n}\right\|^{2}}{\|A\|\left\|\left(I-T_{i}\right) A x_{n}\right\|} \leqslant \frac{\left\|\left(I-T_{i}\right) A x_{n}\right\|^{2}}{\left\|A^{*}\left(I-T_{i}\right) A x_{n}\right\|} .
$$

Then from (3.10), we derive that

$$
\lim _{n \rightarrow \infty}\left\|t_{n}-x_{n}\right\|=\lim _{n \rightarrow \infty}\left\|\left(I-T_{i}\right) A x_{n}\right\|=0 .
$$

Because $\left\{x_{n_{k}}\right\}$ converges weakly to $z$, it implies that $\left\{t_{n_{k}}\right\}$ converges weakly to $z$ as well. Then from (3.10) and the demiclosedness of $\mathrm{I}-\mathrm{U}^{i}$ at zero, we obtain that $z \in \operatorname{Fix}\left(\mathrm{U}_{i}\right)$. Moreover, from $A x_{n_{k}} \rightarrow A z$ as $k \rightarrow \infty$ and (3.10) that the demiclosedness of $I-T_{i}$ at zero, we obtain that $A z \in \operatorname{Fix}\left(T_{i}\right)$. So, $z \in \Gamma$.

Next we derive that $z \in \Gamma$ for $\rho_{n, i}=0$, it follows from $x_{n_{k}} \rightarrow z$ as $k \rightarrow \infty, \lim _{k \rightarrow \infty}\left\|x_{n_{k}}-U^{i} x_{n_{k}}\right\|=0$, that the demiclosedness of $\mathrm{I}-\mathrm{U}^{i}$ at zero, we obtain $z \in \operatorname{Fix}\left(\mathrm{U}^{i}\right)$. Moreover, from continuity of A, we have $A x_{n_{k}} \rightarrow A z$ as $k \rightarrow \infty$. By $\lim _{k \rightarrow \infty}\left\|A x_{n_{k}}-T_{i} A x_{n_{k}}\right\|=0$ and the demiclosedness of $I-T_{i}$ at zero, we obtain that $A z \in \operatorname{Fix}\left(T_{i}\right)$. So, $z \in \Gamma$. Since $z \in \Gamma$, by (3.11) and (2.1), we have

$$
\limsup _{n \rightarrow \infty}\left\langle v-x^{*}, x_{n}-x^{*}\right\rangle=\left\langle v-x^{*}, z-x^{*}\right\rangle \leqslant 0 .
$$

From the definition of $U_{\lambda}$, we have $U_{\lambda_{i}} x-x=\lambda_{i}\left(u^{i} x-x\right)$, for all $x \in H$, it follows that for $\rho_{n, i} \neq 0$

$$
\begin{aligned}
\left\|x_{n+1}-x_{n}\right\| & \leqslant \alpha_{n}\left\|v-x_{n}\right\|+\sum_{i=1}^{\infty} \gamma_{n, i}\left\|u_{\lambda_{i}}^{i} t_{n}-x_{n}\right\| \\
& =\alpha_{n}\left\|v-x_{n}\right\|+\sum_{i=1}^{\infty} \gamma_{n, i}\left\|u_{\lambda_{i}}^{i} t_{n}-t_{n}+t_{n}-x_{n}\right\| \\
& \leqslant \alpha_{n}\left\|v-x_{n}\right\|+\left\|u_{\lambda_{i}}^{i} t_{n}-t_{n}\right\|+\left\|t_{n}-x_{n}\right\| \\
& \leqslant \alpha_{n}\left\|v-x_{n}\right\|+\lambda_{i}\left\|u^{i_{1}} t_{n}-t_{n}\right\|+\left\|t_{n}-x_{n}\right\| .
\end{aligned}
$$

Together with (3.10) and (3.12), which implies that

$$
\lim _{n \rightarrow \infty}\left\|x_{n+1}-x_{n}\right\|=0
$$

By (3.11), we get

$$
\limsup _{n \rightarrow \infty}\left\langle v-x^{*}, x_{n+1}-x^{*}\right\rangle \leqslant 0
$$


Note that for $\rho_{n, i}=0$, we have $t_{n}=x_{n}$ and

$$
\begin{aligned}
\left\|x_{n+1}-x_{n}\right\| & \leqslant \alpha_{n}\left\|v-x_{n}\right\|+\sum_{i=1}^{\infty} \gamma_{n, i}\left\|u_{i_{\lambda_{i}}} x_{n}-x_{n}\right\| \\
& \leqslant \alpha_{n}\left\|v-x_{n}\right\|+\left\|u_{i_{\lambda_{i}}} x_{n}-x_{n}\right\| \\
& =\alpha_{n}\left\|v-x_{n}\right\|+\lambda_{i}\left\|u_{i} x_{n}-x_{n}\right\| .
\end{aligned}
$$

Take on both sides of the inequality limits and by (3.10), we get

$$
\lim _{n \rightarrow \infty}\left\|x_{n+1}-x_{n}\right\|=0
$$

Therefore, by (3.11) we again derive (3.13).

Take $b_{n}=\left\langle v-x^{*}, x_{n+1}-x^{*}\right\rangle$, then $\limsup _{n \rightarrow \infty} b_{n} \leqslant 0$, from Lemma 2.6 and (3.4). Therefore, $\lim _{n \rightarrow \infty} y_{n}=\lim _{n \rightarrow \infty}\left\|x_{n}-x^{*}\right\|=0, x_{n} \rightarrow x^{*}$ as $n \rightarrow \infty$.

Case 2: If $\left\{\left\|x_{n}-x^{*}\right\|\right\}$ is not a monotone sequence, we consider the sequence of the integers $\{\eta(n)\}$ defined by

$$
\eta(n)=\max \left\{k \leqslant n:\left\|x_{k}-x^{*}\right\| \leqslant\left\|x_{k+1}-x^{*}\right\|\right\} .
$$

It is easy to see that $\{\eta(n)\}$ is nondecreasing and when $n \rightarrow \infty$ we get $\eta(n) \rightarrow \infty$. For all $n \geqslant 0$, we obtain $\left\|x_{\eta(n)}-x^{*}\right\|<\left\|x_{\eta(n)+1}-x^{*}\right\|$. Then $\left\{\left\|x_{\eta(n)}-x^{*}\right\|\right\}$ is a monotone sequence and according to Case 1 , we have $\lim _{n \rightarrow \infty}\left\|x_{\eta(n)}-x^{*}\right\|=0$ and $\lim _{n \rightarrow \infty}\left\|x_{\eta(n)+1}-x^{*}\right\|=0$. Finally, from Lemma 2.7, we have

$$
0 \leqslant\left\|x_{n}-x^{*}\right\| \leqslant \max \left\{\left\|x_{n}-x^{*}\right\|,\left\|x_{\eta(n)}-x^{*}\right\|\right\} \leqslant\left\|x_{\eta}(n)+1-x^{*}\right\| \rightarrow 0, \quad n \rightarrow \infty .
$$

Therefore, the sequence $\left\{x_{n}\right\}$ converges strongly to $x^{*}$. This completes the proof of the theorem.

\section{Application: some special cases of GSCFP}

In this section, we consider general split common fixed point problem for some special cases of kdemicontractive operator $(k<1)$. In (1.3),

- $\mathrm{U}^{i}$ is a quasi-nonexpansive operator, if $\mathrm{k}_{\mathrm{i}}=0$;

- $\mathrm{u}^{i}$ is a directed operator, if $\mathrm{k}_{\mathrm{i}}=-1$;

- $T_{i}$ is a quasi-nonexpansive operator, if $\tau_{i}=0$;

- $T_{i}$ is a directed operator, if $\tau_{i}=-1$;

- both $\mathrm{I}-\mathrm{U}^{\mathrm{i}}$ and $\mathrm{I}-\mathrm{T}_{\mathrm{i}}$ are demiclosed at zero.

Let in following $U^{i}, T_{i}$ be the same as above assumptions.

Algorithm 4.1. Choose initial point $x_{0} \in H_{1}$ arbitrarily, and let $\lambda_{i} \in\left(0,1-k_{i}\right)$, the iterative sequence $\left\{x_{n}\right\}$ is generated as follows:

$$
x_{n+1}=\alpha_{n} v+\beta_{n} x_{n}+\sum_{i=1}^{\infty} \gamma_{n, i} u_{\lambda_{i}}^{i}\left(x_{n}-\rho_{n, i} A^{*}\left(I-T_{i}\right) A x_{n}\right), n \geqslant 0,
$$

where $A$ is a bounded linear operator with adjoint $A^{*}$ and the step size $\rho_{n}$ is chosen in such a way that

$$
\begin{cases}\rho_{n, i}=\frac{\left(1-\tau_{i}\right)\left\|\left(I-T_{i}\right) A x_{n}\right\|^{2}}{2\left\|A^{*}\left(I-T_{i}\right) A x_{n}\right\|^{2}}, & A x_{n} \neq T_{i}\left(A x_{n}\right), \\ \rho_{n, i}=0, & \text { otherwise. }\end{cases}
$$

We denote $\Gamma$ that is the set of all solutions of problem GSCFP (1.3).

$$
\Gamma=\left\{x^{*} \in \operatorname{Fix}\left(\mathrm{U}^{\mathrm{i}}\right): A x^{*} \in \operatorname{Fix}\left(\mathrm{T}_{\mathrm{i}}\right)\right\} .
$$


Proposition 4.2. Denote $t_{n}=x_{n}-\rho_{n, i} A^{*}\left(I-T_{i}\right) A x_{n}$, for $\rho_{n, i} \neq 0$, and take an $\hat{x} \in \Gamma$, arbitrarily. We derive from (2.6) and (2.7),

$$
\begin{aligned}
\left\|u_{\lambda_{i}}^{i} t_{n}-\hat{x}\right\|^{2} & \leqslant\left\|t_{n}-\hat{x}\right\|^{2}-\lambda_{i}\left(1-\lambda_{i}-\kappa_{i}\right)\left\|t_{n}-u^{i} t_{n}\right\|^{2} \\
& =\left\|x_{n}-\rho_{n, i} A^{*}\left(I-T_{i}\right) A x_{n}-\hat{x}\right\|^{2}-\lambda_{i}\left(1-\lambda_{i}-\kappa_{i}\right)\left\|t_{n}-u^{i} t_{n}\right\|^{2} \\
& \leqslant\left\|x_{n}-\hat{x}\right\|^{2}-\frac{\left(1-\tau_{i}\right)^{2}}{4} \frac{\left\|\left(I-T_{i}\right) A x\right\|^{4}}{\left\|A^{*}\left(I-T_{i}\right) A x\right\|^{2}}-\lambda_{i}\left(1-\lambda_{i}-\kappa_{i}\right)\left\|t_{n}-u^{i} t_{n}\right\|^{2} \\
& \leqslant\left\|x_{n}-\hat{x}\right\|^{2} .
\end{aligned}
$$

On the other hand, in the case $\rho_{n, i}=0$, then $t_{n}=x_{n}$. We derive from (2.7)

$$
\left\|u_{\lambda_{i}}^{i} x_{n}-\hat{x}\right\|^{2} \leqslant\left\|x_{n}-\hat{x}\right\|^{2}-\lambda_{i}\left(1-\lambda_{i}-\kappa_{i}\right)\left\|x_{n}-u^{i} x_{n}\right\|^{2} \leqslant\left\|x_{n}-\hat{x}\right\|^{2} .
$$

Corollary 4.3. Let $\mathrm{H}_{1}, \mathrm{H}_{2}, \mathrm{~A}, \mathrm{~A}^{*}, \mathrm{U}^{i}, \mathrm{~T}_{\mathrm{i}}, \mathrm{t}_{\mathrm{n}}$ be the same as above, and assume that the solution set $\Gamma$ is nonempty. If the sequences $\left\{\alpha_{n}\right\},\left\{\beta_{n}\right\},\left\{\gamma_{n, i}\right\}$ satisfy the following conditions:

(i) $\alpha_{n}, \beta_{n}, \gamma_{n, i} \in(0,1)$;

(ii) $\alpha_{n}+\beta_{n}+\sum_{i=1}^{\infty} \gamma_{n, i}=1$;

(iii) $\lim _{n \rightarrow \infty} \alpha_{n}=0$ and $\sum_{n=0}^{\infty} \alpha_{n}=\infty$,

then the sequence $\left\{x_{n}\right\}$ generated by Algorithm 4.1 converges strongly to a point $x^{*} \in \Gamma$, where $x^{*}$ is the nearest to $v$, that is $x^{*}=\mathrm{P}_{\Gamma} v$.

\section{Numerical results for SCFP}

In this section, we give an example and several numerical results to illustrate the efficiency of our algorithm.

Example 5.1. Let $H_{1}=H_{2}=R^{2}, i=1,2$, then the iterative method (1.4) becomes

$$
x_{n+1}=\alpha_{n} v+\beta_{n} x_{n}+\left[\gamma_{n, 1} u_{\lambda_{1}}^{1}\left(x_{n}-\rho_{n, 1} A^{*}\left(I-T_{1}\right) A x_{n}\right)+\gamma_{n, 2} U_{\lambda_{2}}^{2}\left(x_{n}-\rho_{n, 2} A^{*}\left(I-T_{2}\right) A x_{n}\right)\right], n \geqslant 0 .
$$

We define the mappings $\mathrm{U}_{\lambda_{1}}^{1}, \mathrm{U}_{\lambda_{2}}^{2}: \mathrm{H}_{1} \longmapsto \mathrm{H}_{1}, \mathrm{~T}_{1}, \mathrm{~T}_{2}: \mathrm{H}_{2} \longmapsto \mathrm{H}_{2}$, and $\mathrm{A}: \mathrm{H}_{1} \longmapsto \mathrm{H}_{2}$ by

$$
\mathrm{U}_{\lambda_{1}}^{1}=\left[\begin{array}{cc}
0.3 & 3 \\
0 & 1
\end{array}\right], \mathrm{U}_{\lambda_{2}}^{2}=\left[\begin{array}{ll}
1 & 0.2 \\
1 & 0.7
\end{array}\right], \mathrm{T}_{1}=\left[\begin{array}{cc}
2 & 3 \\
-1 & 1.4
\end{array}\right], \quad \mathrm{T}_{2}=\left[\begin{array}{cc}
-0.1 & 0.8 \\
-0.6 & 2
\end{array}\right],
$$

and

$$
A=\left[\begin{array}{cc}
2 & 3 \\
1 & -2
\end{array}\right]
$$

where $U_{\lambda_{1}}^{1}=\left(1-\lambda_{1}\right) I+\lambda_{1} U^{1}, u_{\lambda_{2}}^{2}=\left(1-\lambda_{2}\right) I+\lambda_{2} U^{2}, \lambda_{1} \in\left(0,1-k_{1}\right), \lambda_{2} \in\left(0,1-k_{2}\right)$. We have $x^{*}=\{0,0\}$, which satisfies $x^{*} \in \bigcap_{i=1}^{2} \operatorname{Fix}\left(\mathrm{U}^{\mathrm{i}}\right), A x^{*} \in \bigcap_{i=1}^{2} \operatorname{Fix}\left(\mathrm{T}_{i}\right)$.

Let $\alpha_{n}=0.5, \beta_{n}=0.3, \gamma_{n, 1}=0.1, \gamma_{n, 2}=0.2$, then $\alpha_{n}+\beta_{n}+\sum_{i=1}^{2} \gamma_{n, i}=1, \rho_{n, 1}=0.3, \rho_{n, 2}=0.5$. Take $v=\{0.1,0.1\}$ and these parameters satisfy all conditions of Theorem 3.2. Then we present the following algorithm.

Algorithm 5.2. For the case $\rho_{n, i}=0$ :

Step 0: Choose initial point $x_{1} \in\left\{\left(0,1 \times 10^{5}\right),\left(0,1 \times 10^{5}\right)\right\}$ arbitrarily and put $n=0$.

Step 1: Compute $x_{n+1}$ as follows,

$$
x_{n+1}=\alpha_{n} v+\beta_{n} x_{n}+\gamma_{n, 1} u_{\lambda_{1}}^{1} x_{n}+\gamma_{n, 2} u_{\lambda_{2}}^{2} x_{n}, \quad n \geqslant 0 .
$$


Step 2: Set $\left\|x_{n}\right\| \leqslant \varepsilon$ as stop criterion, else set $n=n+1$ and go to Step 1 .

On the other hand, for the case $\rho_{\mathfrak{n}, \mathrm{i}} \neq 0$ :

Step 0: Choose initial point $x_{1} \in\left\{\left(0,1 \times 10^{5}\right),\left(0,1 \times 10^{5}\right)\right\}$ arbitrarily and put $n=0$.

Step 1: Compute $x_{n+1}$ as follows.

$$
x_{n+1}=\alpha_{n} v+\beta_{n} x_{n}+\gamma_{n, 1} u_{\lambda_{1}}^{1}\left(x_{n}-\rho_{n, 1} A^{*}\left(I-T_{1}\right) A x_{n}\right)+\gamma_{n, 2} u_{\lambda_{2}}^{2}\left(x_{n}-\rho_{n, 2} A^{*}\left(I-T_{2}\right) A x_{n}\right), n \geqslant 0 .
$$

Step 2: Set $\left\|x_{n}\right\| \leqslant \varepsilon$ as stop criterion, else set $n=n+1$ and go to Step 1 .

\begin{tabular}{cccc} 
Table 1: $\rho_{\mathrm{n}, \mathrm{i}}=0, \varepsilon=10^{-6}$. & & \\
\hline Initial point & $\chi_{\mathrm{n}+1}$ & Iter. & Time \\
\hline 0.01 & $\left\{1.02139 * 10^{-} 6,6.50878 * 10^{-} 7\right\}$ & 16 & 0.01 \\
0.1 & $\left\{1.11002 * 10^{-} 6,6.94472 * 10^{-} 7\right\}$ & 20 & 0.01 \\
1 & $\left\{6.88956 * 10^{-} 7,4.25804 * 10^{-} 7\right\}$ & 25 & 0.01 \\
10 & $\left\{7.43616 * 10^{-} 7,4.57234 * 10^{-} 7\right\}$ & 29 & 0.01 \\
100 & $\left\{8.01605 * 10^{-} 7,4.91456 * 10^{-} 7\right\}$ & 33 & 0.02 \\
\hline
\end{tabular}

For $\rho_{n, i}=0$, Table 1 presents the number of iterative step, $x_{n+1}$, and CPU time of Algorithm 5.2 with different initial points.

Table 2: $\rho_{n, i}=0, \varepsilon=10^{-6}$.

\begin{tabular}{cccc}
\hline Initial point & $x_{\mathrm{n}+1}$ & Iter. & Time \\
\hline 0.01 & $\left\{4.80227 * 10^{-} 7,3.59497 * 10^{-} 7\right\}$ & 23 & 0.01 \\
0.1 & $\left\{-9.16139 * 10^{-} 7,8.02908 * 10^{-} 8\right\}$ & 24 & 0.01 \\
1 & $\left\{4.45887 * 10^{-} 7,5.15753 * 10^{-} 7\right\}$ & 27 & 0.01 \\
10 & $\left\{8.28239 * 10^{-} 7,4.00402 * 10^{-} 7\right\}$ & 31 & 0.01 \\
100 & $\left\{5.73443 * 10^{-} 7,4.45479 * 10^{-} 7\right\}$ & 36 & 0.02 \\
\hline
\end{tabular}

For $\rho_{n, i} \neq 0$, Table 2 presents the number of iterative step, $x_{n+1}$, and CPU time of Algorithm 5.2 with different initial points.

\section{Conclusions}

The general split common fixed point problem arise in many practical applications in the real world. Many iterative algorithms have been developed to solve them. In this paper, we propose and investigate a new iterative algorithm for solving the GSCFP in the setting of infinite-dimensional Hilbert spaces. Under proper conditions, the theoretical convergence of the algorithm proposed is presented. Several numerical results confirm the effectiveness of the proposed algorithm.

\section{Acknowledgment}

We wish to thank the referees for their helpful comments and suggestions. This research was supported by NSFC Grant (No. 11071279) and National Science Foundation for Young Scientists of China (No. 11501431).

\section{References}

[1] C. Byrne, Iterative oblique projection onto convex sets and the split feasibility problem, Inverse Problems, 18 (2002), 441-453. 1

[2] C. Byrne, A unified treatment of some iterative algorithms in signal processing and image reconstruction, Inverse Problems, 20 (2004), 103-120.1 
[3] Y. Censor, T. Bortfeld, B. Martin, A. Trofimov, A unified approach for inversion problems in intensity-modulated radiation therapy, Phys. Med. Biol., 51 (2005), 2353-2365. 1

[4] Y. Censor, Y. Elfving, A multiprojection algorithm using Bregman projections in a product space, Numer. Algorithms, 8 (1994), 221-239. 1

[5] Y. Censor, Y. Elfving, N. Kopf, T. Bortfeld, The multiple-sets split feasibility problem and its applications for inverse problems, Inverse Problems, 21 (2005), 2071-2084. 1

[6] Y. Censor, A. Segal, The split common fixed point problem for directed operators, J. Convex Anal., 16 (2009), 587-600. 1, 1

[7] R. D. Chen, Fixed point Theory and Applications, National Defence Industry Press, (2012). 2.2

[8] P. L. Combettes, V. R. Wajs, Signal recovery by proximal forward-backward splitting, Multiscale Model. Simul., 4 (2005), 1168-2000. 1

[9] H.-H. Cui, F.-H. Wang, Iterative methods for the split common fixed point problem in Hilbert spaces, Fixed Point Theory Appl., 2014 (2014), 8 pages. 1, 1, 1, 2.4, 2.5

[10] P. E. Maingé, Strong convergence of projected subgradient methods for nonsmooth and nonstrictly convex minimization, Set-Valued Anal., 16 (2008), 899-912. 1, 2.7

[11] A. Moudafi, The split common fixed point problem for demicontractive mappings, Inverse Problems, 26 (2010), 6 pages. 1,1

[12] A. Moudafi, A note on the split common fixed-point problem for quasi-nonexpansive operators, Nonlinear Anal., 74 (2011), 4083-4087. 1, 1

[13] W. Takahashi, Nonlinear functional analysis, Fixed point theory and its applications, Yokohama Publishers, Yokohama, (2000). 2.3

[14] F.-H. Wang, H.-K. Xu, Cyclic algorithms for split feasibility problems in Hilbert spaces, Nonlinear Anal., 74 (2011), 4105-4111. 1, 1

[15] H.-K. Xu, Iterative algorithms for nonlinear operators, J. London Math. Soc., 66 (2002), 240-256. 2.6

[16] Y.-H. Yao, R. P. Agarwal, M. Postolache, Y.-C. Liou, Algorithms with strong convergence for the split common solution of the feasibility problem and fixed point problem, Fixed Point Theory Appl., 2014 (2014), 14 pages. 1

[17] Y.-H. Yao, M. Postolache, Y.-C. Liou, Strong convergence of a self-adaptive method for the split feasibility problem, Fixed Point Theory Appl., 2013 (2013), 12 pages. 1 